\title{
Changes in Photosynthesis and Carbohydrate Metabolism in Mature Apple Leaves in Response to Whole Plant Source-Sink Manipulation
}

\author{
Rui Zhou' ${ }^{1}$ and Bruno Quebedeaux ${ }^{2}$ \\ Department of Natural Resource Sciences and Landscape Architecture, University of Maryland, College \\ Park, MD 20742
} ADDITIONAL INDEX wORDS. Malus sylvestris var. domestica, Sorbitol, sucrose, starch, aldose-6-phosphate reductase, sucrose-
phosphate synthase, ADPGlucose pyrophosphorylase

\begin{abstract}
Photosynthesis and carbohydrate metabolism in apple [Malus sylvestris (L.) Mill. var. domestica (Borkh.) Mansf.] source leaves were monitored during a 7-day period after source-sink manipulations by girdling or partial defoliation treatments. In the girdling treatment, sorbitol, sucrose, glucose, and starch accumulated in leaves, and net photosynthetic rates $(\mathrm{Pn})$ at $350 \mu \mathrm{L} \cdot \mathrm{L}^{-1} \mathrm{CO}_{2}$ decreased during a 7-day period. Pn measured at $1000 \mu \mathrm{L} \cdot \mathrm{L}^{-1}\left[\mathrm{CO}_{2}\right]$ was also decreased but the changes were less. Stomatal conductance and intracellular $\mathrm{CO}_{2}$ concentration decreased markedly in leaves of girdled shoots. When shoots were partially defoliated, starch and glucose concentrations in remaining source leaves declined steadily during the 7-day study period. Sorbitol and sucrose concentrations decreased during the first 2 days after defoliation, then increased the following 5 days. Pn of the remaining leaves measured at ambient and elevated $\mathrm{CO}_{2}$ levels were enhanced markedly. Aldose-6-phosphate reductase activity in source leaves increased markedly from 27.5 to $39.2 \mu \mathrm{mol} \cdot \mathrm{h}^{-1} \cdot \mathrm{g}^{-1}$ fresh weight (FW) after partial defoliation but remained unchanged in leaves after girdling. Selective and maximum sucrose phosphate synthase (SPS) activities increased following partial defoliation and decreased following girdling. ADP-glucose pyrophosphorylase activity remained relatively unchanged in the partial defoliation treatments but increased markedly in the girdled-shoot leaves. These results suggested that girdling-induced photosynthetic inhibition is mainly due to stomatal limitation, however, the photosynthesis enhancement by partial defoliation may be due primarily to acceleration of photosynthetic capacity per se. These studies showed that the metabolism of sorbitol, sucrose and starch, three photosynthetic end products in mature apple leaves, was coordinately regulated in source leaves in response to source-sink manipulations.
\end{abstract}

Photosynthetically fixed carbon in source leaves can be converted to starch and sucrose in most plant species. Starch is synthesized and stored within chloroplasts, and in most plants, it is the primary storage form mobilized for translocation, usually during the night. Sucrose is formed in the cytoplasm and acts as the transport compound for export from source leaves to sink tissues. In some plants, sucrose may also be a storage compound. Carbon allocation between these two pathways not only determines the availability of carbon for export and storage in the leaves, but also may control the rate of photosynthesis (Stitt and Sonnewald, 1995). Reduced sucrose synthesis in spinach leaves was shown to decrease the rate of photosynthesis (Battistelli et al., 1991).

Photosynthesis and carbohydrate metabolism in source leaves respond to sink activity (Aczon-Bieto, 1983; Goldschmidt and Huber, 1992; Krapp and Stitt, 1995; Paul and Driscoll, 1997; Paul and Foyer, 2001; Plaut et al., 1987; Rufty and Huber, 1983). In general, when sink demand increases, photosynthesis is stimulated and more carbon is partitioned to sucrose instead of starch. This process facilitates carbon translocation. On the other hand, when photosynthate transport of source leaves is blocked, photosynthesis is inhibited, sucrose synthesis is reduced, and starch synthesis is stimulated (Dunford, 1998).

The regulation of sucrose and starch metabolism has been extensively studied during the last 2 decades (Preiss and Sivak, 1996; Quick and Schaffer, 1996). Sucrose and starch synthesis are competing reactions and are highly coordinated in vivo

Received for publication 28 Feb. 2002. Accepted for publication 24 Oct. 2002. ${ }^{1}$ Current address: Department of Horticulture, Cornell University, Ithaca, NY 14853 .

${ }^{2}$ To whom reprint requests should be addressed; e-mail bq1@umail.umd.edu.
(Buchanan, 1998). Sink regulation of carbohydrate metabolism in source leaves involves changes in metabolite levels, in the activities of key enzymes for sucrose and starch biosynthesis, and in the transcription of some specific photosynthetic and carbohydrate metabolism genes (Krapp and Stitt, 1995). One model was proposed with respect to this sink regulation. Higher sink demand removes sucrose and favors sucrose-phosphate synthesis catalyzed by sucrose-phosphate synthase (SPS) and the hydrolysis of sucrose-phosphate catalyzed by sucrose phosphatase. The resulting increase in phosphate release in the source cytoplasm leads to increased efflux of triose phosphate from the chloroplast via the triose-phosphate transporter. Glucose-6-phosphate, which is formed from triose phosphate, stimulates the activity of SPS, thus providing sucrose to meet the increased sink demand (Dunford, 1998).

Previously, most investigations on carbon allocation and carbohydrate metabolism have been conducted on plants with sucrose and starch as final photosynthetic end products. In the Rosaceae family, including apple, peach and many other tree fruits, in addition to sucrose and starch, sorbitol is a primary photosynthetic end product. Sorbitol is also the main translocatable carbohydrate in these species (Bieleski, 1982; Loescher and Everard, 1996). The allocation of newly fixed carbon in these species is influenced by the leaf developmental stage (Bieleski and Redgwell, 1985), and environmental conditions, such as water stress (Wang and Stutte, 1992), light intensity (EscoberGutierrez and Gaudillere, 1997), photoperiod (Wang et al., 1997) and $\mathrm{CO}_{2}$ concentration (Pan et al., 1998). Sink strength may also regulate carbohydrate metabolism in the source leaves. Layne and Flore (1995) reported that carbohydrate metabolism in the source leaves of sour cherry changed significantly in response to the source manipulation. As a strong sink organ in some develop- 
mental stages, fruit was also shown to alter the carbohydrate concentrations of source leaves (Nii, 1997; Wibbe and Blanke, 1995). However, the biochemical mechanisms are still unknown with respect to the regulation of carbon allocation in the leaves of these sorbitol-producing plant species.

In the present study, girdling and partial defoliation treatments were applied to young potted apple (Malus sylvestris var. domestica) trees. Girdling, which blocks the photoassimilate transport pathway, resulted in reduced sink demand for carbohydrates from the source leaves. Partial defoliation treatments, with the removal of most source leaves and alteration of the source sink ratio, can cause more carbohydrate demand upon the remaining source leaves by the sink tissues and may allow more carbohydrate export out of the source leaves. The objective of the current studies was to investigate the effects of sink demand on photosynthesis and the activities of key enzymes related to carbohydrate metabolism in apple leaves.

\section{Materials and Methods}

Plant materials. Young apple trees ('Gala' on M9 rootstock) were cut $10 \mathrm{~cm}$ above the bud union in early spring and grown outside of the University of Maryland greenhouse at College Park, Md., under a natural environment from April to June in 20L pots filled with peat-based Professional Growing Medium 300S (Pro-Gro Products, Elizabeth City, N.C.). The trees were then pruned to two shoots per plant with $\approx 30$ leaves on each. The trees were watered twice each day and fertilized weekly with Peters, water soluble $20 \mathrm{~N}-20 \mathrm{P}-20 \mathrm{~K}$ fertilizer at a nitrogen concentration of $470 \mathrm{mg} \cdot \mathrm{L}^{-1}$. The trees were transferred to a growth chamber(BDW36; Conviron, Canada) 3 weeks before the start of the studies. The environmental growth chamber conditions were $15 \mathrm{~h}$ light/ $9 \mathrm{~h}$ darkness, and temperatures of $22^{\circ} \mathrm{C}$ in the light and $18{ }^{\circ} \mathrm{C}$ in the dark. Light was provided with eight $400-\mathrm{W}$ metal halide lamps with 16 additional standard 75-W incandescence lamps (GTE Products Corp., Danvers, Mass) and the light intensity was $\approx 1000 \mu \mathrm{mol} \cdot \mathrm{m}^{-2} \cdot \mathrm{s}^{-1}$ at the studied leaf surface and the relative humidity was kept at $60 \%$.

SoURCE-SINK MANIPULATION. Twelve trees with uniform growth were used for an experiment. Four plants were used for girdling treatments, four for defoliation treatments and the other four were used as control with neither girdling nor defoliation. In the girdling treatment, shoots were girdled by removing $\approx 0.5 \mathrm{~cm}$ width of bark (phloem) with a razor blade at the proximal and basal section of the side branches. Five mature, fully expanded leaves were included between the girdled rings. The cut areas were immediately covered with Parafilm. In the partial defoliation treatment $\approx 90 \%$ of the source leaves were removed from the apple trees. The experiments were repeated twice in two separate growth chambers.

Photosynthesis measurements. Net photosynthetic rates $(\mathrm{Pn})$ of 10 leaves for each treatment tree were measured using a portable photosynthesis system (LI-6400; LI-COR, Lincoln, Nebr.) at $25^{\circ} \mathrm{C}, 1000 \mu \mathrm{mol} \cdot \mathrm{m}^{-2} \cdot \mathrm{s}^{-1}$ light intensity (400 to $700 \mathrm{~nm}$ ) and two $\mathrm{CO}_{2}$ levels $\left(350\right.$ and $\left.1000 \mu \mathrm{L} \cdot \mathrm{L}^{-1}\right)$. Data were pooled to represent the experimental unit. The measurement time was at 6 to $7 \mathrm{~h}$ of the light cycle. Pn was calculated on a leaf area basis as $\left(\mu \mathrm{mol} \mathrm{CO} \mathrm{CO}_{2} / \mathrm{m}^{2} / \mathrm{s}\right)$. Stomatal conductance and the estimated internal $\mathrm{CO}_{2}$ concentration $(\mathrm{Ci})$ were recorded simultaneously. For the determination of $\mathrm{Pn}-\mathrm{Ci}$ curves, the leaf was held in the leaf chamber and the $\mathrm{CO}_{2}$ level was modified from 0 to $1000 \mu \mathrm{L} \cdot \mathrm{L}^{-1}$ at 50 to $100 \mu \mathrm{L} \cdot \mathrm{L}^{-1}$ intervals. The smoothed lines of Pn against $\mathrm{Ci}$ were generated as Pn-Ci curves. Three leaves per treatment were measured for Pn-Ci curves and the typical curve was presented.

Carbohydrate analysis. After the photosynthetic rates were measured, the leaves were harvested and the midrib of each leaf was removed. One half of the leaf was used for carbohydrate analysis and the other half for enzyme extraction and biochemical analyses. Leaf samples for carbohydrate analysis were weighed and immediately frozen in liquid nitrogen, lyophilized and kept at $-80^{\circ} \mathrm{C}$ until analysis. Carbohydrate analysis was conducted as described by Wang et al. (1997). One hundred milligrams of the dried sample was extracted three times, each $20 \mathrm{~min}$, with $2 \mathrm{~mL}$ of $80 \%(\mathrm{v} / \mathrm{v})$ ethanol at $80^{\circ} \mathrm{C}$. The homogenates were centrifuged at $15,000 g_{n}$ for $10 \mathrm{~min}$ to give ethanol-soluble and ethanolinsoluble fractions. The pellets were evaporated to dryness and used for starch determination. The ethanol soluble fractions were pooled and evaporated to dryness with a concentrator (SpeedVac; Savant Instruments, Inc., Farmingdale, N.Y.), and resolublized in $1.5 \mathrm{~mL}$ of deionized water. The soluble fraction was then passed through a Dowex $50 \mathrm{H}^{+}$and a Dowex $1 \mathrm{Cl}^{-}$resin column. The soluble neutral fraction eluted from the two columns with distilled water provided the soluble carbohydrate fraction. Sorbitol, sucrose, glucose and fructose were separated with a high-performance liquid chromatograph (HPLC) (Shimadzu Corp., Columbia, Md.) on a carbohydrate column (HPX-87C; Bio-Rad, Richmond, Calif.) (Wang et al., 1997). Degassed, distilled, deionized water at $0.6 \mathrm{~mL} \cdot \mathrm{min}^{-1}$ at $80^{\circ} \mathrm{C}$ was used as the mobile phase. A refractive index detector (RID-10A; Shimadzu) at $30^{\circ} \mathrm{C}$ was used to quantify sugar content following the separation. Recovery rate was determined with the standard samples of known concentration of glucose, fructose, sucrose and sorbitol. Results showed the recovery rate was high $(>80 \%)$.

For starch analysis, $4 \mathrm{~mL}$ of distilled water was added to the ethanol insoluble fraction, and the resulting suspension was boiled for $30 \mathrm{~min}$ to swell the starch granules. After cooling to room temperature, $1 \mathrm{~mL} 0.1 \%(\mathrm{w} / \mathrm{v})$ amyloglucosidase (EC 3.2.1.3) dissolved in $0.2 \mathrm{M} \mathrm{NaAc-HAc}$ buffer ( $\mathrm{pH} 4.8$ ) was added to hydrolyze the starch to glucose by incubation in a $55^{\circ} \mathrm{C}$ water bath overnight. The digest was centrifuged, the resulting supernatant filtered, and $10 \mathrm{~mL}$ of the filtrate was injected into a Shimadzu HPLC for glucose determination as described above. Spiked samples with the addition of corn soluble starch $(0,0.02$, and $0.2 \mathrm{mg} \cdot \mathrm{mL}^{-1}$, respectively) in the apple leaf insoluble extracts were run to estimate the percentage starch recovery. Apple starch concentration was estimated from the concentration of externally added corn starch (Zhou et al., 2001).

ENZYME EXTRACTION AND ASSAYs. Fresh leaf tissue $(1 \mathrm{~g})$ was ground in an iced precooled mortar and pestle in $10 \mathrm{~mL}$ of extraction buffer (50 mм HEPES-NaOH, pH 7.5, $10 \mathrm{~mm} \mathrm{MgCl}_{2}$, $2.5 \mathrm{~mm}$ DTT, and $1 \mathrm{~mm}$ EDTA) plus $5 \%(\mathrm{w} / \mathrm{v})$ insoluble PVPP and $2 \%(\mathrm{w} / \mathrm{v})$ PEG20. The brei was then filtered through four layers of cheesecloth and centrifuged at 20,000 $g_{n}$ for $10 \mathrm{~min}$. The supernatant was passed through a PD10 column (Pharmacia, Sweden) and eluted with the extraction buffer. The protein portion was collected for enzyme assays.

Aldose-6-phosphate reductase (A6PR, EC 1.1.1.200) was assayed in the direction of sorbitol-6-phosphate synthesis by following the oxidation of NADPH in the presence of glucose-6phosphate (G6P) as described by Negm and Loescher (1981) with minor modifications. One milliliter of reaction mixture contained 0.1 м Tris- $\mathrm{HCl}$ (pH 9.0), 0.1 mм NADPH, 50 mм G6P and $50 \mu \mathrm{L}$ of the extract. The changes in the absorbance at $340 \mathrm{~nm}$ in the first 3 min were monitored and the reacted NADPH was calculated 


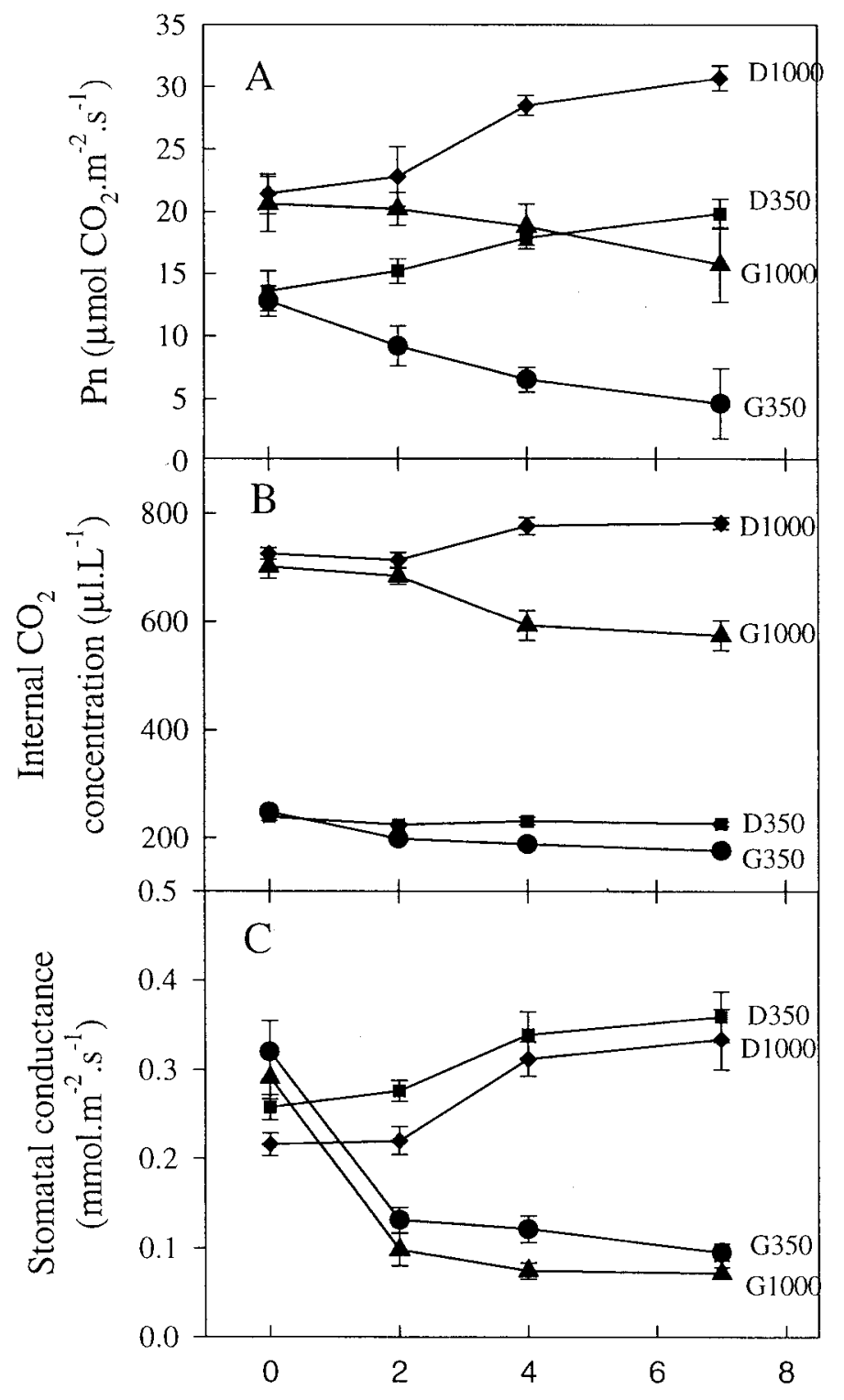

Days after treatments

Fig. 1. Changes in net photosynthetic rates $(\mathrm{Pn})(\mathbf{A})$, internal $\mathrm{CO}_{2}$ concentration $(\mathbf{B})$, and stomatal conductance $(\mathbf{C})$ of fully developed apple leaves in response to source-sink manipulations. The data for the untreated control did not change during the experimental period and are not illustrated here. G350 represents girdling treatment and $350 \mu \mathrm{L} \cdot \mathrm{L}^{-1} \mathrm{CO}_{2}$ concentration. G1000 represents girdling treatment and $1000 \mu \mathrm{L} \cdot \mathrm{L}^{-1} \mathrm{CO}_{2}$ concentration. D350 represents defoliation treatment and $350 \mu \mathrm{L} \cdot \mathrm{L}^{-1} \quad \mathrm{CO}_{2}$ concentration. D1000 represents defoliation treatment and $1000 \mu \mathrm{L} \cdot \mathrm{L}^{-1} \mathrm{CO}_{2}$ concentration. Each data point represents the mean of two repeated experiments $(n=8)$. The vertical bar represents \pm SE of each mean.

with an absorption coefficient of $6.22 \mathrm{~mm}^{-1}$.

Sucrose-phosphate synthase (SPS, EC 2.4.1.14) was assayed according to Huber and Huber (1991) under limiting (selective) and Vmax (maximum) substrate conditions as fructose-6-phosphate (F6P)-dependent formation of sucrose (plus sucrose-P) from UDPG. Under limiting F6P conditions, $20 \mu \mathrm{L}$ of the extract was incubated for $15 \mathrm{~min}$ at $25^{\circ} \mathrm{C}$ with $10 \mathrm{~mm}$ UDPG, $3 \mathrm{~mm} \mathrm{F6P,}$ $10 \mathrm{~mm} \mathrm{Pi}$ (an inhibitor), $50 \mathrm{~mm}$ HEPES-NaOH (pH 7.5), $15 \mathrm{~mm}$ $\mathrm{MgCl}_{2}$, and 2.5 mm DTT in a total volume of $70 \mu \mathrm{L}$. Under Vmax conditions, the assays contained $10 \mathrm{~mm}$ F6P, $40 \mathrm{~mm}$ G6P, and 10
mM UDPG, using identical buffers, volume and reaction time as that of the limiting assays; in addition, the inorganic phosphate was removed from the reaction mixture. All reactions were terminated by the addition of $70 \mu \mathrm{L}$ of $30 \%(\mathrm{w} / \mathrm{v}) \mathrm{KOH}$ and the unreacted F6P was destroyed by placing the tubes in boiling water for $10 \mathrm{~min}$. After cooling, $1.0 \mathrm{~mL}$ of $0.14 \%$ (w/v) anthrone in 13.8 $\mathrm{M} \mathrm{H}_{2} \mathrm{SO}_{4}$ was added and the tubes incubated at $40{ }^{\circ} \mathrm{C}$ for $20 \mathrm{~min}$ before measuring absorbance at $620 \mathrm{~nm}$.

ADP-glucose pyrophosphorylase (AGPase, EC 2.7.7.27) activity was assayed according to Sun et al. (1999) in a reaction mixture containing $80 \mathrm{~mm}$ glycylglycine, $\mathrm{pH} 7.5,5 \mathrm{mM} \mathrm{MgCl}_{2}, 10$ mм NaF, 2.5 mм DTT, 0.5 mm NADP, 1 unit of phosphoglucomutase, 1 unit of glucose-6-phosphate dehydrogenase, $2 \mathrm{~mm}$ ADPG, 4 mm 3-PGA, and $1.5 \mathrm{~mm}$ sodium pyrophosphate. The absorption of the formed NADPH at $340 \mathrm{~nm}$ was recorded without the addition of sodium pyrophosphate (control) and with the addition of sodium pyrophosphate at $25^{\circ} \mathrm{C}$ for $15 \mathrm{~min}$.

Statistical analysis. Statistical analyses were performed using SAS procedures (SAS Institute Inc., Cary, N.C.). Due to the insignificant difference between the data from the two growth chambers, data from the two experiments were pooled and analyzed. The points presented in the figures represent means of the eight replications of single tree experimental units. The standard errors of the means for all the replications were calculated and are presented.

\section{Results}

EFFECTS OF SOURCE-SINK MANIPULATIONS ON PHOTOSYNTHESIS IN APPLE LEAVES. The girdling treatments reduced $\mathrm{Pn}$ from 12.8 to $4.6 \mu \mathrm{mol} \mathrm{CO}_{2} / \mathrm{m}^{2} / \mathrm{s}$ under ambient $\left[\mathrm{CO}_{2}\right]\left(350 \mu \mathrm{L} \cdot \mathrm{L}^{-1}\right)$ over a $7-\mathrm{d}$ period (Fig. 1A). Pn measured at $1000 \mu \mathrm{L} \cdot \mathrm{L}^{-1} \mathrm{CO}_{2}$ also decreased but the relative change was less. Pn declined $<10 \%$ during the first $4 \mathrm{~d}$ after treatment (from 20.6 to $18.8 \mu \mathrm{mol} \mathrm{CO}_{2} / \mathrm{m}^{2} / \mathrm{s}$ ), and decreased by $\approx 24 \%$ by the seventh day of the experimental period in the girdling treatment compared to the initial Pn rate before the girdling treatment.

Pn of apple leaves was significantly enhanced under ambient and elevated $\mathrm{CO}_{2}$ concentrations with the partial defoliation treatments (Fig. 1A). It increased from 13.6 to 19.8 at $350 \mu \mathrm{L} \cdot \mathrm{L}^{-1}$ $\mathrm{CO}_{2}$ level and from 21.4 to 30.7 at $1000 \mu \mathrm{L} \cdot \mathrm{L}^{-1} \mathrm{CO}_{2}$ at the end of the experimental period.

The internal $\mathrm{CO}_{2}$ concentration (Ci) (Fig. 1B) and stomatal conductance (Fig. 1C) of the apple leaves also changed significantly in response to source-sink manipulations. A decrease in $\mathrm{Ci}$ was observed under ambient $\mathrm{CO}_{2}$ levels and higher $\mathrm{CO}_{2}$ levels in the girdling treatments. The $\mathrm{Ci}$ level was reduced from 247.4 to $175.6 \mu \mathrm{L} \cdot \mathrm{L}^{-1}$ in $7 \mathrm{~d}$ at $350 \mu \mathrm{L} \cdot \mathrm{L}^{-1} \mathrm{CO}_{2}$ concentration (Fig. 1B). In contrast, Ci remained relatively unchanged at ambient $\mathrm{CO}_{2}$ levels but increased slightly from 726 to $782 \mu \mathrm{L} \cdot \mathrm{L}^{-1}$ at $1000 \mu \mathrm{L} \cdot \mathrm{L}^{-1} \mathrm{CO}_{2}$ level within one week in the partial defoliation treatments.

After shoot girdling the stomatal conductance declined from 0.320 to $0.131 \mathrm{mmol} \cdot \mathrm{m}^{-2} \cdot \mathrm{s}^{-1} 2 \mathrm{~d}$ after treatments under ambient $\mathrm{CO}_{2}$ levels and continued to decrease in the following days. The changes in stomatal conductance under elevated $\mathrm{CO}_{2}$ showed similar patterns as that of ambient $\mathrm{CO}_{2}$ conditions. On the other hand, partial defoliation treatments significantly increased stomatal conductance of the remaining source leaves from 0.258 to $0.359 \mathrm{mmol} \cdot \mathrm{m}^{-2} \cdot \mathrm{s}^{-1}$ over the 7-d experimental period (Fig. 1C).

Girdling treatments inhibited and partial defoliation treatments stimulated $\mathrm{Pn}$ as indicated in the $\mathrm{Pn}-\mathrm{Ci}$ response curve (Fig. 2). The maximum Pn rates were reduced $\approx 20 \%$ in the girdled 


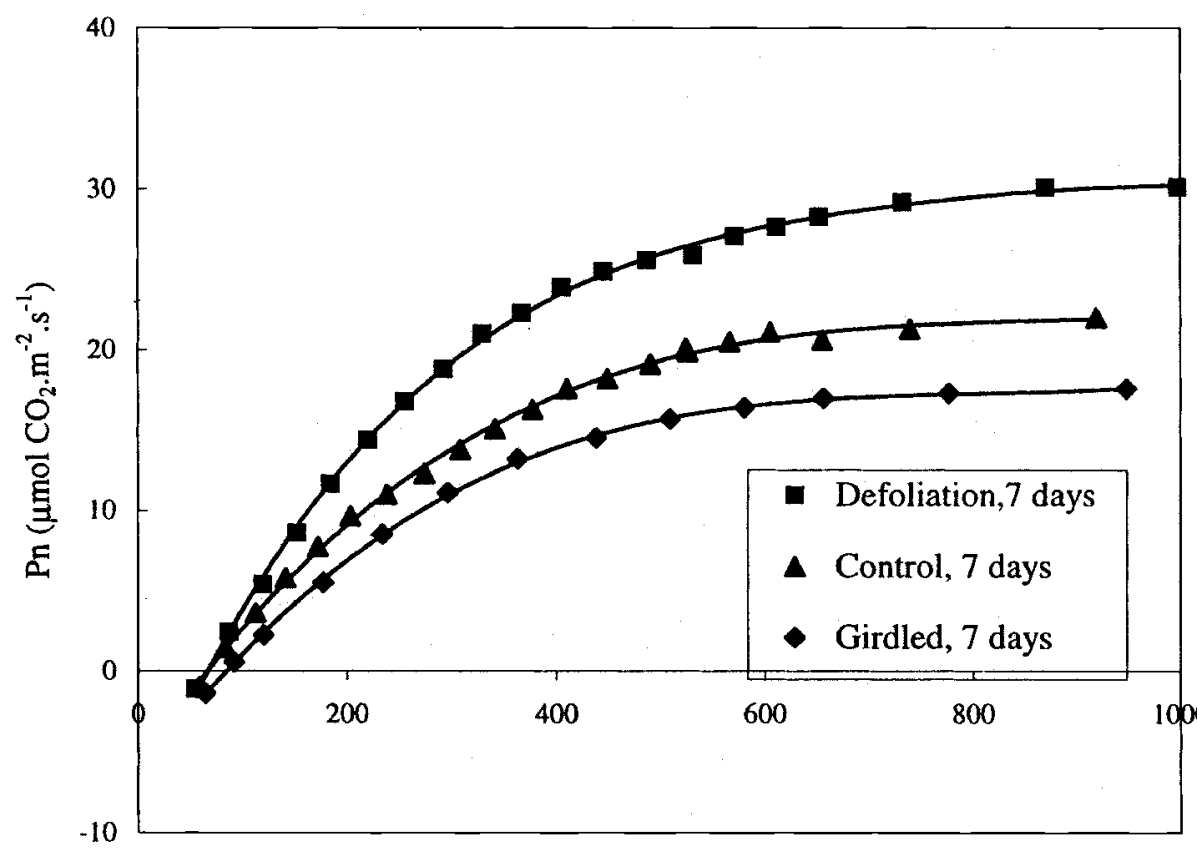

Ci Concentration $\left(\mu \mathrm{l} . \mathrm{L}^{-1}\right)$
A6PR and SPS activities were enhanced in the remaining source apple leaves with the partial defoliation treatments (Fig. 4B). A6PR activity increased from 27.6 to 37.2 $\mu \mathrm{mol} \cdot \mathrm{h}^{-1} \cdot \mathrm{g}^{-1} \mathrm{FW}$ during the 7 -d experimental period. Maximum and selective SPS activities increased $36 \%$ and $32 \%$, respectively, during that period. AGPase showed no significant changes.

\section{Discussion}

SinK REgUlation OF PHOTOSYNTHESIS. In this study, shoot girdling resulted in the accumulation of carbohydrate in source leaves and a concomitant decrease in photosynthetic rates, while partial defoliation resulted in a decline in source leaf carbohydrate concentration and an increase in photosynthetic rates. These results suggest an end-product control of photosynthesis in apple leaves.

The mechanism(s) for end-product regulation of photosynthesis are controversial. Our data suggest that the regulatory mecha-
Fig. 2. The calculated Pn-Ci response curves of fully developed apple leaves in response to source sink manipulations. Each point represents the mean of the typical results from the two repeated experiments.

leaves and was enhanced $37 \%$ in the remaining source leaves of partially defoliated trees.

EFFECTS OF GIRDLING AND PARTIAL DEFOLIATION ON NONSTRUCTURAL CARBOHYDRATE LEVELS IN APPLE LEAVES. Girdling treatments presumably inhibited photosynthate export and thereby resulted in the accumulation of sorbitol, sucrose, glucose, fructose and starch in leaves (Fig. 3A). The largest relative changes occurred in starch concentration, which increased from 2.3 to $22.2 \mathrm{mg} \cdot \mathrm{g}^{-1} \mathrm{FW}$ over the 7 -d experimental period. Sorbitol and sucrose levels increased $\approx 57 \%$ and $21 \%$, respectively, while glucose levels increased significantly from 4.2 to $5.1 \mathrm{mg} \cdot \mathrm{g}^{-1} \mathrm{FW}$. No significant changes were observed for fructose levels.

Partial defoliation resulted in a decrease in sorbitol concentrations from 16.3 to $11.8 \mathrm{mg} \cdot \mathrm{g}^{-1} \mathrm{FW}$ in the first $2 \mathrm{~d}$ after treatments followed by recovery to $15.4 \mathrm{mg} \cdot \mathrm{g}^{-1} \mathrm{FW}$ by the $7^{\text {th }}$ day (Fig. 3B). Sucrose concentrations showed a similar pattern of change over the 7-d experimental period. However, the concentrations of starch and glucose decreased steadily by $48 \%$ and $27 \%$, respectively, compared to the untreated control (Fig. 3B).

Changes in the aCtivities of A6PR, SPS, AND AGPase IN APPLE LEAVES IN RESPONSE TO SOURCE-SINK MANIPULATIONS. After girdling the shoot, AGPase activity in apple leaves increased significantly from 42.9 to $56.0 \mu \mathrm{mol} \cdot \mathrm{h}^{-1} \cdot \mathrm{g}^{-1} \mathrm{FW}$ over the experimental period (Fig. 4A). A6PR activity was $28.6 \mu \mathrm{mol} \cdot \mathrm{h}^{-1} \cdot \mathrm{g}^{-1} \mathrm{FW}$ during the first day and remained relatively unchanged throughout the 7 experimental days. Two kinds of SPS activities were determined in the present study, one is maximal SPS activity, which is determined with saturating substrate and activator conditions. Another is selective SPS activity, which is assayed with limiting substrate concentrations and the inhibitor, Pi (Huber and Huber 1991). Maximal SPS activity decreased from 28.4 to $18.7 \mu \mathrm{mol} \cdot \mathrm{h}^{-1} \cdot \mathrm{g}^{-1} \mathrm{FW}$ and selective SPS activity declined from 18.6 to $11.8 \mu \mathrm{mol} \cdot \mathrm{h}^{-1} \cdot \mathrm{g}^{-1} \mathrm{FW}$ over the experimental period (Fig. 4A).

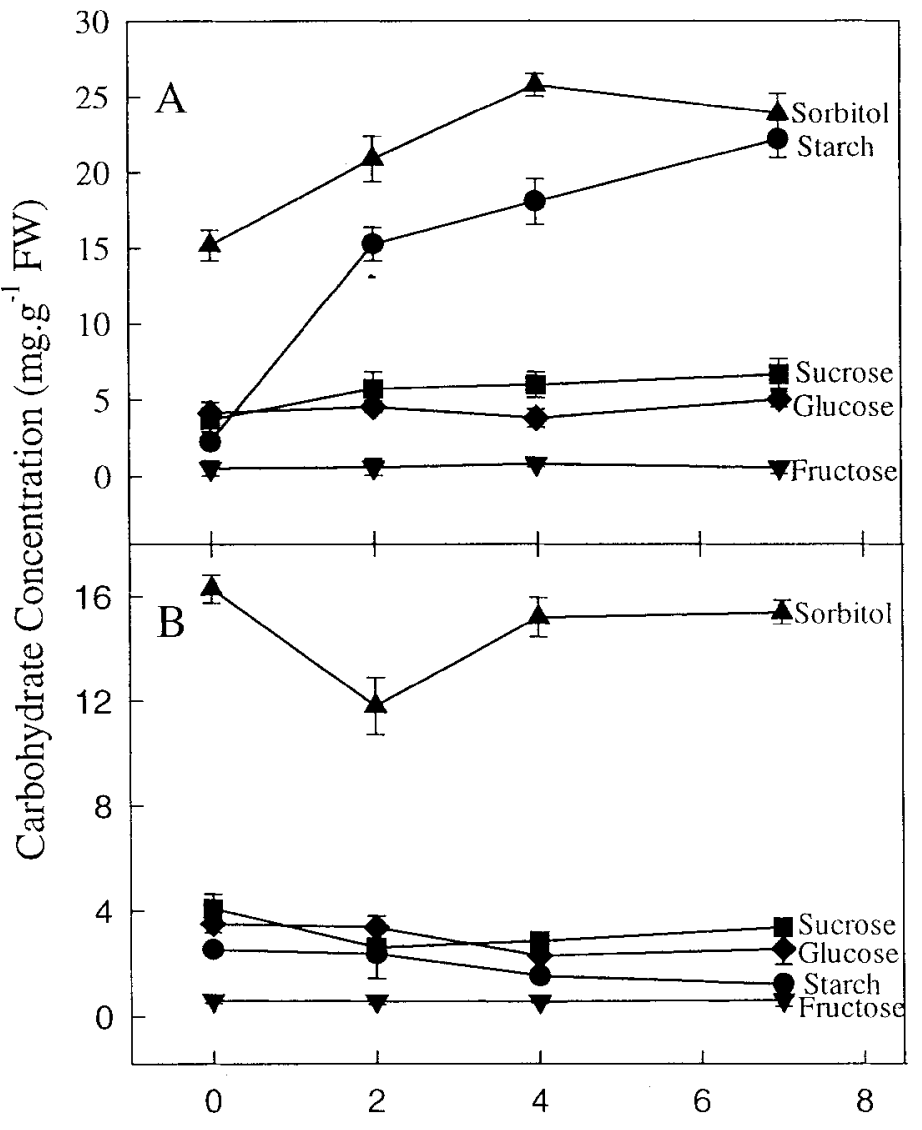

Days after treatments

Fig. 3. Changes in carbohydrate concentrations in fully developed apple leaves after (A) girdling treatment and (B) after partial defoliation treatment. The data for the untreated control did not change during the experimental period and are not illustrated here. Each data point represents the mean of two repeated experiments $(n=8)$. The vertical bar represents \pm SE of each mean. 


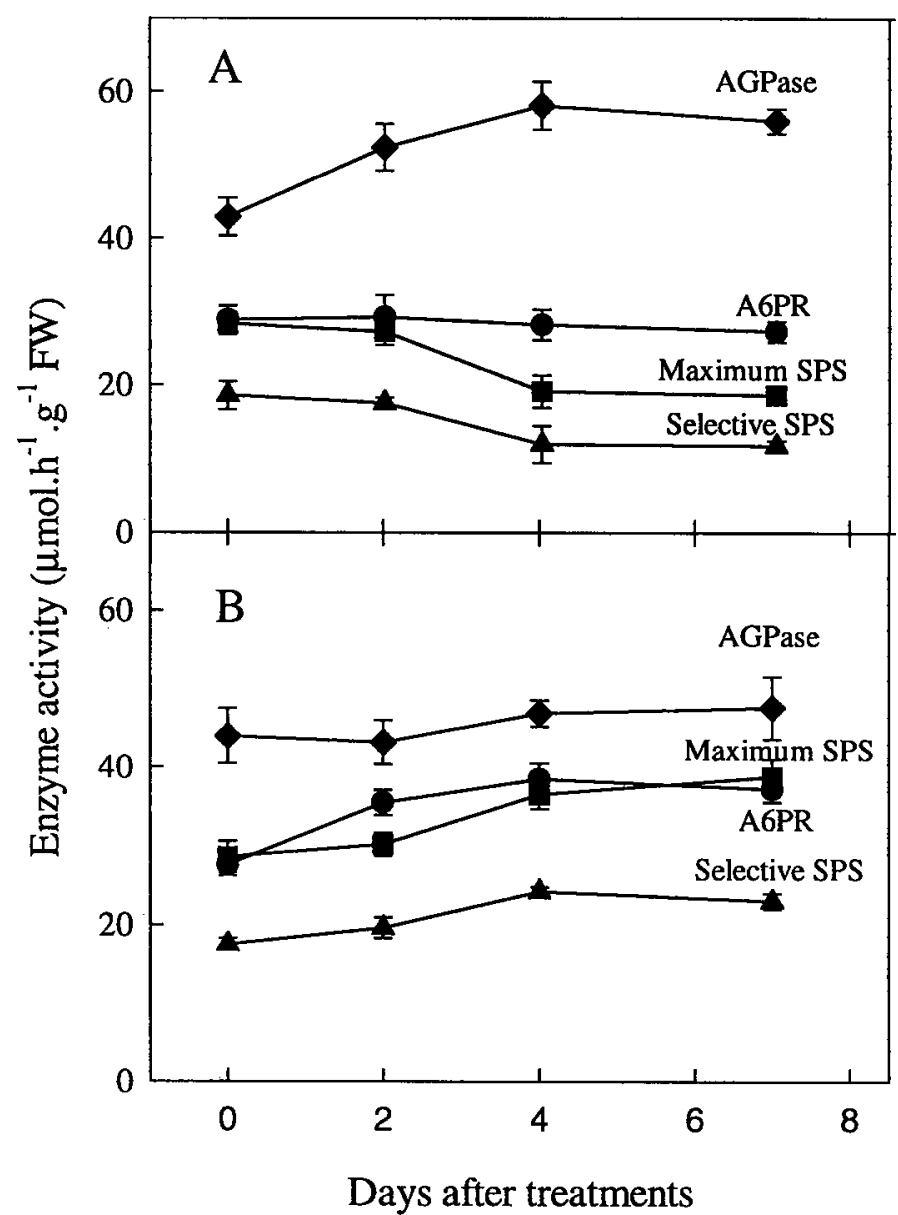

Fig. 4. Changes in activities of A6PR, SPS, and AGPase in apple fully developed leaves (A) after girdling treatment and (B) after partial defoliation treatment. The data for the untreated control did not change during the experimental period and are not illustrated here. Each data point represents the mean of two repeated experiments $(n=8)$. The vertical bar represents \pm SE of each mean.

nisms in apple leaves are different under the conditions of carbohydrate accumulation and carbohydrate depletion. In the girdling treatments, in parallel with the accumulation of carbohydrates, stomatal conductance and internal $\mathrm{CO}_{2}$ concentration decreased, and $\mathrm{Pn}$ rates under ambient $\mathrm{CO}_{2}$ concentration decreased by $80 \%$ compared with the control. In contrast, maximum Pn rates only decreased by $\approx 20 \%$. Maximum Pn was measured at $1000 \mu \mathrm{L} \cdot \mathrm{L}^{-1} \mathrm{CO}_{2}$ concentration and the internal $\mathrm{CO}_{2}$ concentration under these conditions was shown to be higher than the saturation point (Fig. 1B and Fig. 2), suggesting the stomatal limitation was bypassed. These data indicated that the stomatal limitation could account for most of the photosynthesis inhibition observed under ambient $\mathrm{CO}_{2}$ conditions. Several reports demonstrated that the decrease in Pn could be related to a decrease in osmotic potential in photosynthetic leaf cells (Heineke et al., 1992; Lee and Daie, 1997). The accumulation of soluble carbohydrates including sorbitol, sucrose and glucose in the present study suggested that there may be a decrease in osmotic potential of mature apple leaves after the shoot girdling treatment.

The increase in maximum Pn of the remaining source leaves in the partial defoliation treatment suggested that the photosynthetic capacity was stimulated by the partial defoliation treatments. The observed photosynthetic enhancement following partial defoliation may have been due to the enhancement of Rubisco activity. As shown in Fig 2, the initial slope of the Pn-
Ci curve of apple leaves in this treatment increased significantly compared to that of the control plants. The initial slope was reported to be related to in vivo Rubisco activity (Cheng and Fuchigami, 2000; von Caemmerer and Farquhar, 1984).

Plant species vary greatly in susceptibility to photosynthesis inhibition after hot-girdling or sink removal (Goldschmidt and Huber, 1992; Plaut et al., 1987). Starch accumulators showed serious Pn inhibition with a more than $50 \%$ decrease in maximum Pn with hot-girdling treatments. In contrast, sucrose accumulators showed almost no changes in maximum $\mathrm{Pn}$ in this case. Intermediate plants responded to girdling treatments by moderate inhibition of maximum Pn (Goldschmidt and Huber, 1992). Our results indicate that apple leaf Pn responses to girdling treatments are similar to that of intermediate plants.

The present study demonstrated that starch accumulated the most among all the five investigated nonstructural carbohydrates in mature apple leaves in response to shoot girdling. There are two opposing theories for the function of starch in photosynthesis. One proposes that starch accumulation is responsible for the feedback inhibition of photosynthesis and the mechanism involves possible mechanical damage of the chloroplast by large starch grains (Grub and Machler, 1990; Nafziger and Koller, 1976). Recently more evidence indicates that starch synthesis is essential for photosynthesis and is not responsible for inhibition of photosynthesis (Ludewig et al., 1998; Sun et al., 1999). Our results suggest starch accumulation in apple leaves may play a role in apple leaf photosynthesis.

Regulation OF STARCH SYNTHESIS. There are at least two hypotheses reported for leaf starch synthesis, the overflow model and the programmed model. The overflow model suggests that starch is an overflow product when photosynthesis is high. As photosynthesis increases, sucrose synthesis saturates first and the starch synthesis system is triggered (Eichelmann and Laisk, 1994). Other studies suggested starch synthesis is programmed to meet the increased demand for carbon (Geiger et al., 1985). Both models may operate in the leaves depending on the environmental conditions (Sun et al., 1999). Our results suggest that starch may act as an overflow product for carbon flux in apple leaves. When the carbohydrate export is blocked or reduced, more carbon is partitioned into starch. This allows for carbon accumulation without a dramatic accompanying decrease in osmotic potential in leaves. Other studies in our laboratory also supported this speculation (Pan et al., 1998; Wang et al., 1999).

The observed stimulation of starch accumulation by the blockage of photoassimilate transport was related to increases in AGPase activity (Fig. 4A). AGPase is a key enzyme for starch biosynthesis in higher plants (Preiss and Sivak, 1996). Krapp and Stitt (1995) reported that inhibition of photosynthate export may regulate starch synthesis via changes in gene expression. Along with the accumulation of starch, the transcript for the small subunit of AGPase was shown to increase steadily in spinach leaves after cold girdling was applied to spinach petioles. Similar results were obtained in autotrophic Chenopodium rubrum cells, and tobacco and spinach leaves with different methods to increase the carbohydrate content (Krapp and Stitt, 1994).

Regulation OF SUCROSE AND SORBITOL SYNTHESIS. In the current study, the concentrations of soluble carbohydrates, including sorbitol and sucrose, decreased in the first $2 \mathrm{~d}$ in the source leaves after partial defoliation treatments and increased thereafter. The variation in sugar level in leaves is the balance of sugar synthesis, translocation and utilization. Immediately after the partial defoliation treatment, the sudden increase in sink 
demand for carbohydrates from the remaining source leaves was not accompanied by a simultaneous increase in sugar synthesis, leading to decreases in both sorbitol and sucrose concentrations in the source leaves. After $2 \mathrm{~d}$, as the plants adjusted to the sourcesink manipulation, the activities of A6PR and SPS were stimulated and leaf photosynthetic rates were significantly enhanced, and more carbon may have subsequently been converted into sorbitol and sucrose.

SPS is a key enzyme for sucrose synthesis, and its activity is controlled by multiple mechanisms (Huber and Huber, 1996). Apple SPS has been partially purified and characterized (Zhou et al., 2002). In our current study, when demand for carbohydrates from the remaining source leaves was increased by partial defoliation, both maximum SPS activity and selective SPS activity increased. They declined when the demand for carbohydrate from the source leaves was limited by shoot girdling. The alteration of SPS activity to the changes in demand for carbohydrate suggests that, as in other herbaceous species, SPS may be one of the control points of carbon allocation between the various photosynthetic end products in apple leaves.

The observed changes in sorbitol concentrations reported here may be due to changes in sorbitol biosynthesis and/or export. A6PR is a key enzyme for sorbitol biosynthesis (Loescher and Everard, 1996). Developmental, diurnal and seasonal studies of apple seedlings and leaves have shown that increased A6PR activity is correlated with the development of photosynthetic capacity and sorbitol accumulation in green tissues (Loescher et al., 1982; Yamaki and Ishikawa, 1986; Zhou et al., 2001). Our present results revealed that A6PR activity was associated with the source sink manipulation in apple trees. Sorbitol is the primary transport compound. Increased A6PR activity and acceleration of sorbitol synthesis in the remaining leaves is essential for apple plant growth and development in the partial defoliation treatment. The mechanism of the upregulation of A6PR activity by sink demand needs to be investigated further.

\section{Literature Cited}

Azcon-Bieto, J. 1983. Inhibition of photosynthesis by carbohydrates in wheat leaves. Plant Physiol. 73:681-686.

Battistelli, A., M.D. Adcock, and R.C. Leegood. 1991. The relationship between the activation state of sucrose phosphate synthase and the rate of $\mathrm{CO}_{2}$ assimilation in spinach leaves. Planta 183:620-622.

Bieleski, R.L. 1982. Sugar alcohols, p. 158-192. In: F.A. Loewus and W. Tanner (eds.). Encyclopedia of plant physiology. New series. vol 13A. Springer-Verlag, New York.

Bieleski, R.L. and R.J. Redgwell. 1985. Sorbitol versus sucrose as photosynthesis and translocation products in developing apricot leaves. Austral. J. Plant Physiol. 12:657-668.

Buchanan, B.B. 1998. Photosynthesis, p. 195-225. In: L. Taiz and E. Zeiger(eds.). Plant physiology. Sinauer Assoc., Inc., Publ., Sunderland, Mass.

Cheng, L. and L.H. Fuchigami. 2000. Rubisco activation state decreases with increasing nitrogen content in apple leaves. J. Expt. Bot. 51:16871694

Dunford, S. 1998. Translocation in the phloem, p. 251-285. In: L. Taiz and E. Zeiger (eds.). Plant physiology. Sinauer Assoc., Inc., Publ., Sunderland, Mass.

Eichelmann, H. and A.H. Laisk. 1994. $\mathrm{CO}_{2}$ uptake and electron transport rates in wild-type and a starchless mutant of Nicotiana sylvestris. The role and regulation of starch synthesis at saturating $\mathrm{CO}_{2}$ concentrations. Plant Physiol. 106:679-687.

Escobar-Gutierrez, A.J. and J.P. Gaudillere. 1997. Carbon partitioning in source leaves of peach, a sorbitol synthesizing species, is modified by photosynthetic rate. Physiol. Plant. 100:353-360.
Goldschmidt, E.E. and S.C. Huber. 1992. Regulation of photosynthesis by end-product accumulation in leaves of plants storing starch, sucrose, and hexose sugars. Plant Physiol. 99:1443-1448.

Geiger, D.R., L.M. Jablonski. and B.J. Ploeger. 1985. Significance of carbon allocation to starch in growth of Beta vulgaris, p. 289-308. In: R.L. Heath and J. Preiss (eds.). Regulation of carbon partitioning in photosynthetic tissue. Amer. Soc. Plant Physiol., Rockville, Md.

Grub, A. and F. Machler. 1990. Photosynthesis and light activation of Rubisco in the presence of starch. J. Expt. Bot. 41:1293-1301.

Heineke, D., U. Sonnewald, D. Bussis, G. Gunter, K. Leidreiter, I. Wike, K. Raschke, L. Willmitzer, and H.W. Heldt. 1992. Expression of yeastderived invertase in the apoplast of potato plants results in an inhibition of photosynthesis caused by an increase of the osmotic pressure in leaf cells due to the accumulation of hexoses and amino acids, and affects an increase in the protein to starch ratio in the tubers. Plant Physiol. 100:301-308.

Huber, S.C. and J.L.A. Huber. 1991. Regulation of maize leaf sucrose phosphate synthase by protein phosphorylation. Plant Cell Physiol. 32:319-326.

Huber, S.C. and J.L.A. Huber. 1996. Role and regulation of sucrosephosphate synthase in higher plants. Annu. Rev. Plant Physiol. Plant Mol. Biol. 47:431-444.

Krapp, A. and M. Stitt. 1994. Influence of high carbohydrate content on the activity of plastidic and cytosolic isoenzyme pairs in photosynthetic tissues. Plant Cell Environ. 17:861-866.

Krapp, A. and M. Stitt. 1995. An evaluation of direct and indirect mechanisms for the "sink-regulation" of photosynthesis in spinach: Changes in gas exchanges, carbohydrates, metabolites, enzyme activities and steady-state transcript levels after cold-girdling source leaves. Planta. 195:313-323.

Lee, J.S. and J. Daie. 1997. End-product repression of genes involving carbon metabolism in photosynthetically active leaves of sugar beet. Plant Cell Physiol. 38:887-894.

Layne, D.R. and J.A. Flore. 1995. End-product inhibition of photosynthesis in Prunus cerasus L. in response to whole-plant source-sink manipulation. J. Amer. Soc. Hort. Sci. 120:583-599.

Loescher, W.H. and J.D. Everard. 1996. Sugar alcohol metabolism in sinks and sources, p. 185-207. In: E. Zamski, and A.A. Schaffer (eds.). Photoassimilate distribution in plants and crops: Source-sink relationships. Marcel Dekker, New York.

Loescher, W.H., G.C. Marlow, and R.A. Kennedy. 1982. Sorbitol metabolism and sink-source interconversions in developing apple leaves. Plant Physiol. 70:335-339.

Ludewig F., U. Sonnewald, F. Kauder, D. Heineke, M. Geiger, M. Stitt, B.T. Muller-Rober, B. Gillissen, C. Kuhn, and W.B. Frommer. 1998. The role of transient starch in acclimation to elevated atomospheric $\mathrm{CO}_{2}$. FEBS Lett. 429:147-151.

Nafzinger, E.D. and R.M. Koller. 1976. Influence of leaf starch concentration on $\mathrm{CO}_{2}$ assimilation in soybean. Plant Physiol. 57:560-563.

Negm, F.B. and W.H. Loescher. 1981. Characterization and partial purification of aldose-6-phosphate reductase (alditol-6-phosphate : NADP 1oxidoreductase) from apple leaves. Plant Physiol. 67:139-142.

Nii, N. 1997. Changes of starch and sorbitol in leaves before and after removal of fruits from peach trees. Ann. Bot. 79:139-144.

Pan, Q., Z. Wang, and B. Quebedeaux. 1998. Response of the apple plant to $\mathrm{CO}_{2}$ enrichment: Changes in photosynthesis, sorbitol, and other soluble sugars, and starch. Austral. J. Plant Physiol. 25:293-297.

Paul, M.J. and S.P. Driscoll. 1997. Sugar repression of photosynthesis: The role of carbohydrates in signalling nitrogen deficiency through source:sink imbalance. Plant Cell Environ. 20:110-116.

Paul, M J. and C.H. Foyer. 2001. Sink regulation of photosynthesis. J. Expt. Bot. 52:1383-1400.

Plaut, Z., M.L. Mayoral, and L.Reinhold. 1987. Effect of altered sinksource ratio on photosynthetic metabolism of source leaves. Plant Physiol. 85:786-791.

Preiss, J. and M. Sivak. 1996. Starch synthesis in sinks and sources, p. 63-95. In: E. Zamski, and A.A. Schaffer (eds.). Photoassimilate distribution in plants and crops: Source-sink relationships. Marcel 
Dekker, New York.

Quick, W.P. and A.A. Schaffer. 1996. Sucrose metabolism in sources and sinks, p. 115-156. In: E. Zamski and A.A. Schaffer (eds.). Photoassimilate distribution in plants and crops: Source-sink relationships. Marcel Dekker, New York.

Rufty, T.W. and S.C. Huber. 1983. Changes in starch formation and activities of sucrose phosphate synthase and cytoplasmic fructose-1,6bisphosphatases in response to source-sink alterations. Plant Physiol. 72:474-480.

Stitt, M. and U. Sonnewald. 1995. Regulation of metabolism in transgenic plants. Annu. Rev. Plant Physiol. Plant Mol. Biol. 46:341-368.

Sun. J., T.W. Okita, and G.E. Edwards. 1999. Modification of carbon partitioning, photosynthetic capacity, and $\mathrm{O}_{2}$ sensitivity in Arabidopsis plants with low ADP-glucose pyrophosphorylase activity. Plant Physiol. 119:267-276.

von Caemmerer, S. and G.D. Farquhar. 1984. Effects of partial defoliation, changes of irradiance during growth, short-term water stress and growth at enhanced $\mathrm{p}\left(\mathrm{CO}_{2}\right)$ on the photosynthetic capacity of leaves of Phaseolus vulgaris L. Planta 160:320-329.

Wang, Z., Q. Pan, and B. Quebedeaux. 1999. Carbon partitioning into sorbitol, sucrose, and starch in source and sink apple leaves as affected by elevated $\mathrm{CO}_{2}$. Environ. Expt. Bot. 41:39-46.

Wang, Z. and G.W. Stutte. 1992. The role of carbohydrates in active osmotic adjustment in apple under water stress. J. Amer. Soc. Hort. Sci. 117:816-823.

Wang, Z., Z. Yuan, and B. Quebedeaux. 1997. Photoperiod alters diurnal carbon partitioning into sorbitol and other carbohydrates in apple. Austral. J. Plant Physiol. 24:587-597.

Wibbe, M.L. and M.M. Blanke. 1995. Effects of defruiting on sourcesink relationship, carbon budget, leaf carbohydrate content and water use efficiency of apple trees. Physiol. Plant. 94:529-533.

Yamaki, S. and K. Ishikawa. 1986. Roles of four sorbitol related enzymes and invertase in the seasonal alteration of sugar metabolism in apple tissue. J. Amer. Soc. Hort. Sci. 111:134-137.

Zhou, R., R.C. Sicher, and B. Quebedeaux. 2001. Diurnal Changes in carbohydrate metabolism in mature apple leaves. Austral. J. Plant Physiol. 28:1143-1150.

Zhou, R., R.C. Sicher, and B. Quebedeaux. 2002. Apple leaf sucrosephosphate synthase is inhibited by sorbitol-6-phosphate. Funct. Plant Biol. 29:569-574. 